\title{
Hesitation Strategies in an Oral L2 Test among Iranian Students Shifted from EFL Context to EIL
}

\author{
Shadi Khojastehrad ${ }^{1}$ \\ ${ }^{1}$ Faculty of modern languages and communication, University Putra Malaysia, Malaysia \\ Correspondence: Shadi Khojastehrad, Faculty of modern languages and communication, University Putra \\ Malaysia, Malaysia. E-mail: khojasteh.shadi@yahoo.com
}

Received: March 27, 2012

doi:10.5539/ijel.v2n3p10

\author{
Accepted: April 19, 2012 Published: June 1, 2012 \\ URL: http://dx.doi.org/10.5539/ijel.v2n3p10
}

\begin{abstract}
English as an international language emphasizes on learning different major dialect forms; in particular, it aims to equip students with the linguistic tools to communicate internationally. English is no longer merely used by native speakers but by all those who come to use it.

The study reported in this paper was conducted in the population of Iranian students in the academic context of Malaysia who have learned English as a foreign language in their home country, but after immigrating to the multi lingual country of Malaysia have to use it as an International language to communicate not only with the academician but also with the common people. This shift of English language application had led them to a confusion, which reveals in in their performance, although they are not quite aware of the involving reasons.

Therefore, this study examined this mismatch between EFL and EIL oral performance from the angle of hesitation, and investigated the hesitation strategies Iranian university students use while they are speaking English. It focused on the frequency and distribution of pauses, pauses and fillers, and fillers in the speech of 12 Persian speakers of English, students in a public university in Kuala Lumpur, Malaysia, participating in an oral test consisting of three parts to study whether the type of questions affect the hesitation strategies they employ or not. The data collected was collected and analyzed qualitatively and quantitatively, and the results indicated that Persian speakers of English follow different pausing conventions which varied by the change in the context of the questions.
\end{abstract}

Keywords: EIL, EFL, hesitation, filler, pauses, disfluency, oral test

\section{Introduction}

Since 1970s, communication strategies have been one of the major research topics in Second Language Acquisition (SLA). Faerch and Kasper (1983) were the pioneers in proposing that communication strategies are verbal plans within a speech production framework. A psycholinguistic approach was adapted to their study, and they emphasized on two stages of production: "a planning phase and an execution phase". (Prinyajaran, 2008: p. 2).The planning phase is a stage when a plan is developed to achieve a communicative goal. During this stage, the language user chooses rules and items which can best carry out the plan to achieve"proper" verbal behavior meeting with the original communication goals. Actually, communication strategies are accounted as a part of the planning process, which are resorted by the learners in case of a problem in executing the first plan. (Faerch \& Kasper, 1983) (Prinyajaran, 2008: p. 2)

Concerning the fact that very few of us can speak completely fluently without changing our minds, producing perfectly eloquent wordings without any hesitation or slips, we can admit that spontaneous speech naturally includes pauses, hesitations, "err words, truncated words, repetitions, prolonged sounds, repairs, etc.

As Crystal and Davy (1979) mention "There is some sense in the idea that one of the very first things to learn in a foreign language is how to hesitate in it." (Schmid, Groningen, Fa“gersten, \& H“ogskola, 2010: p. 5)

\subsection{What Is Meant by Hesitation?}

Hesitations have been known as pauses with varying length, which are not usually left unfilled. They usually occur when a speaker is in lack of words or struggling with cognitive or perhaps verbal planning. Obviously, native speakers fill the hesitation fillers by various fillers including non-lexical fillers like lengthening or 
stretching sounds, quasi-lexical fillers, repeating one or several lexical items, and finally lexical fillers. (Rieger, 2003)

\subsection{What Is Meant by Disfluencies?}

Disfluencies have been known as strategic devices which signal an interlocutor of the speaker's under construction utterance. It has also been characterized as the automatic effect resulting from cognitive burdens, specially while managing speech production as doing other tasks. (Nicholson, Gurman, Lickley, Anderson, Mullin, Kenicer, \& Smallwood, 2003)

Obviously, spontaneous speech contains all kinds of disfluency phenomena such as silent pauses, hesitations, repetitions, fillers, grammatical errors, mis-selected lexical items, self-corrections, prolongations, false starts, slips of the tongue, etc., which occur because of disharmony between speech planning and execution stage. In fact, speech disfluencies are defined as phenomena interrupting the flow of speech without adding propositional contents to an utterance. (Menyhárt, 2003)

\subsection{Function of Disfluencies and Hesitation}

Studies have shown that disfluencies have several different functions and motivations. Some researchers have shown that pause fillers (e.g. English 'uh' and 'um') serve a discourse function regarding turn taking. In fact, Clark and Fox Tree admit their lexical goal by claiming that "their communicative function will be lost if they are simply not recognized". (Lai, Gorman, Yuan, \& Liberman, 2007: p. 1)

Other researchers have discovered that silent pauses are produced to facilitate breathing, but at the same time enable the speaker to harmonise his/her speech processes, and allow listeners to comprehend and digest what they have heard, however, some disfluency phenomena appear as "errors", which almost distract listeners. Recently, a study on hesitations and disfluencies in speech, showed there is an instance of disfluency per six words in spontaneous speech although in longer monologues the frequency reaches to every 3.6 words. ( this count does not include silent pauses) (Menyhárt, 2003)

According to Maclay \& Osgood (1959) filled pauses can be used to establish control of the conversational "ball". They may be used to take the control of the conversation away from the counterpart of the interaction (Murata, 1994). Also, a filled pause can be used to keep a conversational turn; to ensure no one is taking over one's turn.

In most of the studies, FPs have been categorized under the large class of hesitation disfluncies which includes false starts, restarts, and silent pauses, filled pauses.(Maclay \& Osgood, 1959)

If a speaker "pauses long enough to receive the cue of his own silence, he will produce some kind of signal ([m, er]) which says, in effect, 'I'm still in control—don't interrupt me!'” (Maclay \& Osgood, 1959: p. 41)

Beattie (1977) investigated on this phenomenon in some naturally-occurring conversations. He found out that interruptions were emerging more considerably during silent pauses rather than in the presence of filled pauses.

Apart from looking after the speech discourse structure, speakers need to signal the beginning and ending of their conversational turns to others. It is commonly believed that interlocutors are freer to interrupt in interactive situations rather than the public situations. Therefore, it is absolutely significant for the speakers to maintain the control of the conversation, where FPs are of great use proactively but at the same time cooperatively. (Ralph, 2008: p. 7)

The classification of the different functions of unfilled and filled pauses under cognitive/non-language-specific, and semantic/language-specific groups is supported by how the native speakers perceive L2 learners. It has been already discussed that the frequency and specially the distribution of unfilled pauses might influence negatively on the L2 learners' proficiency level perceived by native judges, (Dewaele, 1996; Lennon, 1990; Trofimovich \& Baker, 2006) even though using typical hesitation markers result in sounding like proficient. (Dewaele, 1996; Lennon, 1990) (Schmid et al., 2010)

Moreover, researches have shown that hesitation pause group is not really homogenous. In particular, silent pauses emerge in a really different pattern from that of the filled pauses. For example, silent pauses (and other hesitation pauses excluding filled pauses) represent speaker's anxiety more than filled pauses. (Goldman-Eisler, 1961; Kasl \& Mahl, 1965; Krause \& Pilisuk, 1961; Mahl, 1956; Ragsdale, 1976). It can be simply inferred that listeners who judge about highly frequent hesitation negatively, build their negativity based on filled pauses, rather than the other hesitation pauses, or even the interaction between filled pauses and other hesitation pauses. (Ralph, 2008: p. 2) 


\subsection{Previous Studies on Hesitation}

Hieke was one of the pioneers who discovered that non-native speakers use more self-repairs rather than native speakers. Wiese found out in his study, which was focused on self-repair in L1 and L2 production that L1 and L2 production are different processes. Wiese also showed that L2 speakers employ bigger number of self-repairs rather than L1 speakers. He discussed that L2 speakers' error in speech is more than L1 speakers', and L2 speakers tend to correct their errors more than L1 speakers attempt to. He also proposed that L2 speakers require more time to plan their contributions due to the inadequate knowledge of their L2, and they show less automatization in processing their second language.

On the other hand, O'Connor studied the speech of beginning and advanced L2 learners and found out that beginners do not use bigger number of self-repairs rather than the advanced learners. However, they employ various kinds of self-repair such as producing more corrective repairs rather than anticipatory repairs although advanced learners utilize more anticipatory self-repairs.

Temple focused on self-repair in the speech of L1 and beginner L2 users. She analysed speech and self-repair frequency in both groups and found out that native speakers seem to speak twice faster than non-native speakers do; because of the frequent and skilful application of fillers. In contrast, the non-native speakers mostly leave their hesitation pauses unfilled, produce more false starts, and leave more errors uncorrected in comparison with the native speakers. (Rieger, 2003)

Although disfluencies cannot be separated from the spontaneous speech, listeners still discard repetitions and filled pauses easily. In fact, disfluencies are a cross linguistic fact of life, which have not been affected by inter-language differences in distributions. (La, Gorman, Yuan, \& Liberman, 2007: p. 1)

\subsection{Mechanism of Disfluencies}

Disfluencies usually occur in stuttering, blocks, prolongations, hesitations; (part of/complete) word repetitions, and self-corrections. These are related to self-monitoring processes in which speakers check their speech quality. In fact, this hypothesis entails the individuals who stutter. This group finds many planning problems within their internal speech, and it leads to disfluencies which come from attempting to correct them. In general, monitoring accounts consider continuity between those who stutter and those who do not: disfluencies in both groups are caused by the same mechanisms, which emerge more frequently among those who stutter. The phonological deficiencies cause a lot of phonological speech errors internally which are identified and edited by the speaker's self-monitor. In fact disfluencies are the product of editing phase (interrupting and restarting), and the kind of disfluency depends on the moment of interruption. (Robert, Hartsuiker, Corley, Lickle, \& Russels, 2003)

In another perspective to view the mechanism of disfluencies and hesitation, it has been proposed that when a speaker selects a word, other phonologically related and similar words like the intended word are activated. At first, the activation of all these words is similar, although when the activation is complete, the intended word gets to a higher asymptotic value at last. Kolk \& Postma discuss that in case a response is made during the phase when activation is in process (rather than at full activation), the probability of competing rather than selecting the intended word increases which finally leads to error occurrence. They suggest that a speaker recognizes these errors by the use of the perceptual system in case they are produced overtly, and at this stage a monitor which exists in the learner's linguistic system responds by interrupting and starting correction. Thus, word repetition and hesitation (not actually errors in themselves) have been considered as indicators of underlying errors which are identified and interrupted before speech output comes up with overt errors. (Howell, 2003) According to editor theories of monitoring, there is a monitoring system in the speaker's cognitive which demands the existence of an editor to replace incorrect speech output through the production processes. It is likely that the editor itself contains a system of rules on its own which checks the output. (Kormos, 1999)

\subsection{The Significance of Communication Strategies in Speech}

Recent research findings in SLA have argued that employing particular strategies plays an important role in learning the target language (e.g., McDonough, 1995; Oxford, 1996). Many scholars believe that metacognitive strategies focusing on raising the learner's awareness of the learning process may improve L2 skills (Cohen, 1998; O’Malley \& Chamot, 1990; Wenden, 1991). Moreover, it has also been discussed that developing communication strategies can enhance learners' communicative skills. (e.g., Cohen, Weaver, \& Li, 1998; Dornyei, 1995). It seems reasonable to hypothesize that learners' oral proficiency can be improved by raising strategy awareness to be utilized for solving potential communication problems. (Nakatani, 2005: p1)

Furthermore, it has also been proposed that using communicationstrategies can improve learners' skills for interpersonal communication. (Nakatani, 2005: p. 4) 
It has been argued that FPs in spontaneous speech are used by both speakers and listeners systematically, and meaningfully. In fact, FPs are not solely interruptions in message transfer, but they are also symbolic elements of communication. In particular, their use is motivated by the application of various pragmatic constraints resulting in increased cognitive effort. Knowledge about the appropriate and inappropriate use of FPs in speech should build some part of a speaker'scommunicative competence.

According to Canale and Swain (1980) communicative competence consists of three components: grammatical, sociolinguistic, and strategic competence. Grammatical competence refers to the mastery of the linguistic code. Sociolinguistic competence is attributed to the knowledge of appropriate application of language in a given setting, and finally strategic competence encompasses the skills to overcome the shortcomings in grammatical competence.Practically, speakers resort to their inventory of communication strategies-devices to solve the communication problems to operationalize their strategic competence. This might include some linguistic techniques like circumlocution or even non-linguistic techniques such as gesture. (Ralph, 2008: p. 8)

According to D"ornyei (1995) and Dula (2001) using fillers and other hesitation devices in speech are actually application of communication strategies. Using these strategies contribute to compensating for speech processing problems by giving the speaker a chance to gain time during speech which finally leads to building effective communication by signalling the continuity of speech through producing some appropriate vocal indicatives of hesitation.

In fact, FPslike well, hmm, let's see, and, and so- are categorized as lexical fillers and hesitation devices. D"ornyei (1995) and Dula (2001) argue that fillers and hesitation devices should be taught as communication strategies in language programs. The main and the most obvious function of disfluency markers are attributed to thecognitive processes which have been also known as "symptom" function (Levelt, 1989, see also Clark \& Fox Tree, 2002; Fox Tree \& Clark, 1997).

Similar studies have shown that disfluency markers are indicatives of lexical or information retrieval problems which the speakers encounter with in the mid-utterances. In other words, the speaker interrupts her/his own flow of speech in order to backtrack or perhaps repeat some linguistic units while planning for the next stretch of discourse.Researchers have proposed that "symptomatic"or "cognitive"hesitations have pragmatic and discursive functions which even contribute to the fluency of spontaneous speech, making the speaker able to improve in content organization. (Chafe, 1985; Garrett, 1975; Levelt, 1983, 1989; Mayer, 1999; Shattuck-Hufnagel \& Klatt, 1979; Ward, 2004). This suggestion is confirmed by the result of a study which showed that the frequency of some hesitation markers is in accordance with how much the speaker involves in speech planning or deals with the cognitive difficulties (Bock, 1986; Bock \& Levelt, 1994; Butterworth \& Beattie, 1978; Chafe, 1980; Crystal, 1982; Garrett, 1975; Goldman-Eisler, 1968; Maclay \& Osgood, 1959; Rochester, 1973; Shriberg, 2001; Van-Winckel, 1982). (Schmid, et al., 2010: p. 2)

Moreover, speakers may use disfluency markers mainly for semantic purposes. According to de Leeuw (2007), when disfluency markers are used for semantic purposes, "they lend emphasis to a specific discourse element in order to structure their speech , or "convey a message" to a listener, or reflect the inner cognitiveprocesses of the speaker". This semanticfunction has also been called the "signal" function (de Leeuw, 2007, p. 88; see also Clark \& Fox Tree, 2002).Based on this view, hesitation markers facilitate comprehension or influence on meaning interpretation.(Ball, 1975; Brennan \&Schober, 2001; Brennan \& Williams,1995; Christenfeld, 1995; Fox Tree, 2002; Maclay \& Osgood, 1959; Schachter, Christenfeld, Ravina, \& Bilous, 1991; Shriberg, 1996; Swerts, Wichmann, \& Beun, 1996). (Schmid et al.,: p3)

Concerning the difference between cognitive and semantic discourse markers, Clark \& Fox Tree (2002) it has been discovered that the entity of hesitation in filled pauses are different from disfluency markers by being linguistic signals, or words. This almost explains that filled pauses are mainly related to the semantic function of discourse markers, although the other hesitation discourse markers like silent pauses, retractions, repetitions - are most often used as strategies in order to solve the cognitive problems. This pattern was also investigated and showed the same findings in two experiments which were attempting to compare the use of filled and unfilled pauses between the speakers of American English and German (O'Connell \& Kowal, 1972; O'Connell, Kowal, \& H"ormann, 1969). (Schmid et al., 2010)

Despite all the above explained contributions of FPs to the flow of speech, it is not easy to change the common intuition that FPs affects listeners negatively. We need to first consider ourselves instead of the listener. Obviously, we do not always pay attention when speakers use FPs, and sometimes we may hardly ever notice to these discourse markers. This phenomenon which is known as filtering, proposed by Martin \& Strange (1968) and Shriberg (1994), can point toward an explanation. As we are listening to a speaker, we might notice a lot of 
things like individual words, or syntactic structures, or in some cases we might be attracted by the pronunciation of each phoneme, the message content, or even the discourse organization. In some cases, we may even pay attention to non-linguistic signals such as gestures, body position, and even the speaker's hair color during her talk. However, we, as listeners, are mostly concerned with what the speaker has intended to say rather than the other information which is as much processed to facilitate conveying the message.(Ralph, 2008: p. 3)

In fact, we cannot deny the contribution of FPs to overall communicative competence. There are some pragmatic constraints allowing the speaker further processing time. Knowing how these constraints interact with communication strategies is actually a part of a speaker's sociolinguistic competence. (Ralph, 2008: p. 9)

\subsection{Lack of Teaching FPs in Language Curriculum}

Despite the significance of learning hesitation strategies as a type of communication strategies, the lack of teaching FPs is still felt in the language teaching curriculum which can be explained by three reasons: Firstly,since FPs are believed to be commonly occurring when the speaker is attempting to decide what to say next; therefore, they are regarded as a byproduct of speech planning, although they might signal speech production processes as suggested by Dalton \& Hardcastle (1977), Færch \& Kasper (1983), Goldman-Eisler, (1961). However, it does not imply that they are meaningless. (Ralph, 2008: p1) A second reason may rise from the fact that the application of FPs in speech - especially in public speaking cases - is downgraded. Negative judgments about the speakers who employ FPs in L2 speech suggest the inter-language effect of learners' first language on the second which causes linguistic inefficiency in the target language. Thus, those who disagree with incorporating the training of FPs discuss that we should not handicap the leaners more in oral speech by instructing them how to produce such these overt elements of disfluency. (Ralph, 2008: p. 1)

Finally the third reason can be attributed to the lack of research on FPs in language studies in comparison with the vast investigations done in this domain by clinical, behavioral psychologists, sociolinguists.

Regardless of the fact that learners might use FPs in their speech, they definitely hear native speakers to be using FPs quite regularly. In fact, almost all native speakers they interact with at any length use FPs. (Ralph, 2008: p. 2)

\section{Materials \& Methods}

\subsection{Participants}

In order to investigate which pragmatic markers Iranian EFL learners use during hesitation, the researcher selected the population of TEP (Tertiary English Program) students in a public university in Kuala Lumpur, Malaysia, who had already taken the IELTS exam and received a score of 5.5. Thus, the language competence of the population was almost the same, but their language background needed to be checked for a higher congruency scale. The instrumentation which was used at this stage was a LBQ (language background questionnaire) questionnaire, which helped the researcher to identify the most congruent participants regarding their language background.

Finally, respondents including six males and six females whose dominant language was their first language, Persian, and had not grown up as a bilingual, but learned L2 initially at a school, and then continued in language institutes or private classes in their home country were selected.

Each participant had to take part in an oral L2 test consisting of 4 parts: Introduction, Conversation (General) Questions, Retelling a passage, and Picture description for 10-12 minutes. The collected data yielded about 140 minutes of English interaction between the student as the subject and the researcher as the interviewer.

\subsection{Research Instrument}

The research instruments which were used in this study included a Language Background Questionnaire to find the most congruent subjects regarding their language background, twelve unseen passages to give them to read and retell after a limited time, twelve unseen pictures to show them randomly for a description based on their imagination, and finally 3 sets of general questions extracted from the assessment database of a language institute with their permission.

\subsection{Data Collection and the Procedure of the Present Study}

In collecting the data, the researcher recorded the sessions and afterwards tried to transcribe the recording of the interview session including all the pauses and incoherent sounds the respondents had produced, and it was checked for several times in order not to skip even a short silent pause. Then she identified the hesitation strategies used and coded them as drawling, pauses, repeating words, using hesitation filler words and producing 
incoherent vocals. Not all pragmatic markers like "I think" indicated hesitation strategy, so the researcher had to ensure of the hesitation function they had to list them among the identified hesitation strategies.

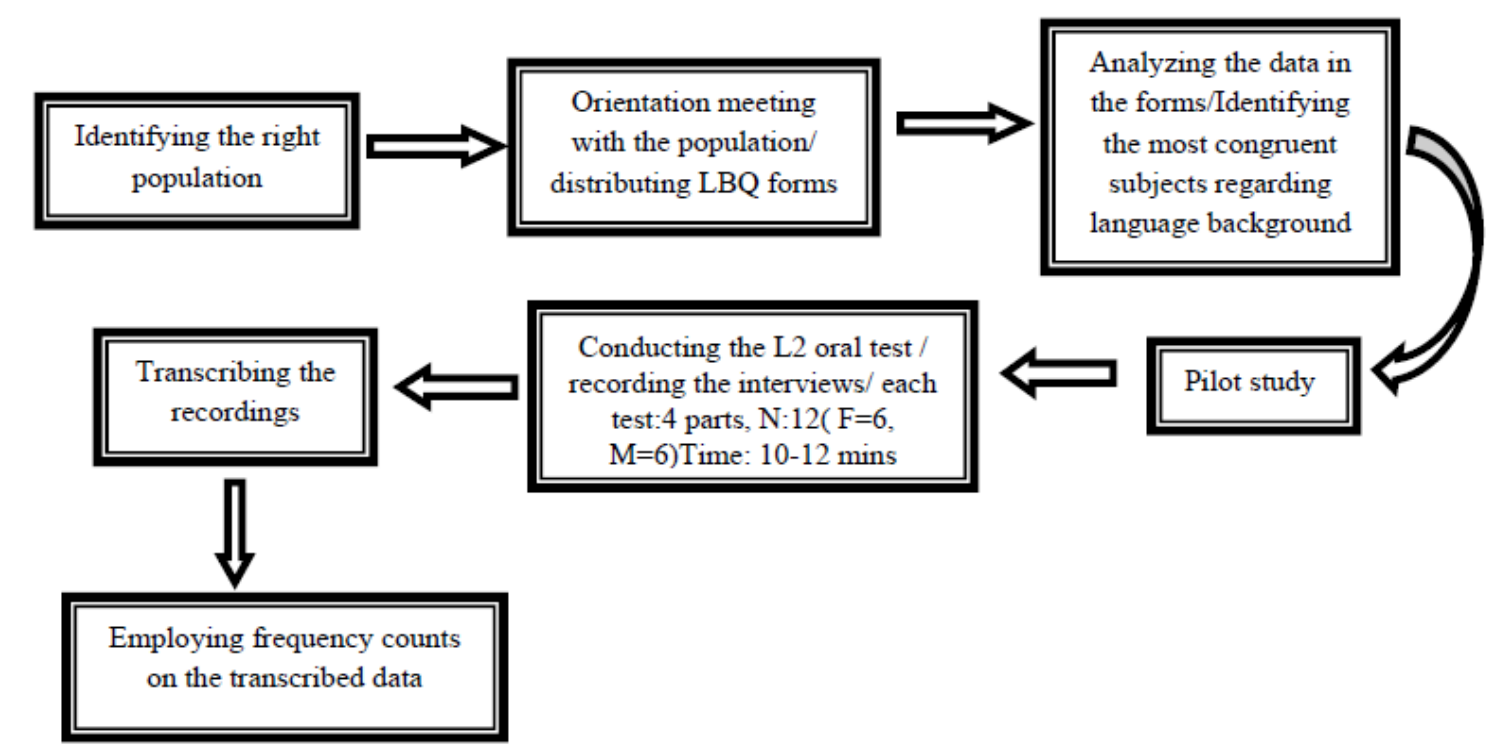

Figure 1. Procedure of the study

\subsection{Method}

The sessions were digitally recorded. Based on the findings of the pilot study to contribute to the reliability of the results, the participants were required to read the passages, given by the researcher, in a timely manner of only one minute to get a gist of as much as they had read as the third section of their interview. The subject of the passages varied, so that the general idea of the texts could not be passed and shared among participants. The topics centered on social, historical, and environmental issues.

Each session began with some explanations about the format of the test by the researcher, and proceeded with conversation questions as the second part, retelling a passage was the third part, and finally describing a picture was the fourth part of the test.

\section{Results}

\subsection{Variable Coding}

The variables selected for coding, inspired in large part by Vincent (1993) and Andersen (2001) which are summarized in the following table and explanation.As the analysis on the transcribed data showed, the Iranian EFL learners tended to use the following pragmatic markers for hesitation in L2 oral performance.

\subsubsection{Dependent Variable: Discourse Markers of Hesitation}

a) Hesitation Fillers as incoherent Vocals likeeee, uuh, mmm, eem, uum

b) Hesitation Filler Words including like"I think", "you know", and "well"

c) Pauseswhich are actually unfilled gaps during speech

d) Repeated Words which refer to repeating the prompt word(s) of the interviewer at the beginning of the utterance or some of their own words during speech

e) Drawling which refers to lengthening the vowels

The abbreviation of the above which will be used in this report is as following:

HFV: Hesitation Filler VocalsP: Pauses $\quad$ D: Drawling RW: Repeated Words

HFW: Hesitation FillerWords

The result of the analysis on the transcribed data is summarized in Table 1. 
Table 1. The whole data table of produced hesitation discourse markers

\begin{tabular}{|c|c|c|c|c|c|c|c|c|c|c|}
\hline \multirow{3}{*}{ Row } & \multirow{3}{*}{ name } & \multicolumn{9}{|c|}{ Discourse Markers of Hesitation } \\
\hline & & \multicolumn{5}{|c|}{ Hesitation fillers as vocals } & \multirow[t]{2}{*}{ H F W } & \multirow[t]{2}{*}{$\mathrm{D}$} & \multirow[t]{2}{*}{$\mathrm{P}$} & \multirow[t]{2}{*}{ RW } \\
\hline & & Eee & uuh & emm & $\mathrm{mmm}$ & umm & & & & \\
\hline 1 & Parisa & $\sqrt{ }$ & $\sqrt{ }$ & $\sqrt{ }$ & $\sqrt{ }$ & $\sqrt{ }$ & $\sqrt{ }$ & - & $\sqrt{ }$ & $\sqrt{ }$ \\
\hline 2 & Homa & $\sqrt{ }$ & - & $\sqrt{ }$ & $\sqrt{ }$ & $\sqrt{ }$ & $\sqrt{ }$ & $\sqrt{ }$ & $\sqrt{ }$ & $\sqrt{ }$ \\
\hline 3 & Ayda & $\sqrt{ }$ & - & - & $\sqrt{ }$ & - & - & $\sqrt{ }$ & $\sqrt{ }$ & $\sqrt{ }$ \\
\hline 4 & Faranak & $\sqrt{ }$ & - & - & $\sqrt{ }$ & - & $\sqrt{ }$ & $\sqrt{ }$ & $\sqrt{ }$ & - \\
\hline 5 & Maliheh & $\sqrt{ }$ & - & - & $\sqrt{ }$ & - & $\sqrt{ }$ & $\sqrt{ }$ & $\sqrt{ }$ & $\sqrt{ }$ \\
\hline 6 & Samaneh & $\sqrt{ }$ & - & - & $\sqrt{ }$ & - & $\sqrt{ }$ & $\sqrt{ }$ & $\sqrt{ }$ & $\sqrt{ }$ \\
\hline 7 & Farhad & $\sqrt{ }$ & $\sqrt{ }$ & - & $\sqrt{ }$ & - & $\sqrt{ }$ & $\sqrt{ }$ & $\sqrt{ }$ & - \\
\hline 8 & Soheyl & $\sqrt{ }$ & - & - & $\sqrt{ }$ & - & $\sqrt{ }$ & $\sqrt{ }$ & $\sqrt{ }$ & $\sqrt{ }$ \\
\hline 9 & Amir & $\sqrt{ }$ & - & $\sqrt{ }$ & $\sqrt{ }$ & - & - & - & $\sqrt{ }$ & - \\
\hline 10 & Yousef & $\sqrt{ }$ & - & $\sqrt{ }$ & $\sqrt{ }$ & - & $\sqrt{ }$ & $\sqrt{ }$ & $\sqrt{ }$ & $\sqrt{ }$ \\
\hline 11 & Adnan & $\sqrt{ }$ & $\sqrt{ }$ & $\sqrt{ }$ & $\sqrt{ }$ & - & $\sqrt{ }$ & $\sqrt{ }$ & $\sqrt{ }$ & $\sqrt{ }$ \\
\hline \multirow[t]{3}{*}{12} & Alireza & $\sqrt{ }$ & $\sqrt{ }$ & - & $\sqrt{ }$ & - & $\sqrt{ }$ & $\sqrt{ }$ & $\sqrt{ }$ & $\sqrt{ }$ \\
\hline & Total & $12 / 12$ & $4 / 12$ & $5 / 12$ & $12 / 12$ & $2 / 12$ & $10 / 12$ & $10 / 12$ & $12 / 12$ & $9 / 12$ \\
\hline & Percentage & $100 \%$ & $33.3 \%$ & $41.6 \%$ & $100 \%$ & $16.6 \%$ & $83.3 \%$ & $83.3 \%$ & $100 \%$ & $75 \%$ \\
\hline
\end{tabular}

As the findings show, all of the participants of the study produced the Hesitation Filler Vocal of "eee" and "mmm", and also paused (kept quiet) while thinking about what and how to say next.

The second mostly used hesitation strategy belongs to hesitation filler words, and drawling with the percentage of almost $84 \%$. Repeated words showed a lower rate of $75 \%$. Following the statistics above, we can notice that less than half of the participants, which makes up $41.6 \%$ of the total number, uttered "emm" while hesitating, but then with a slight difference we can see only $33.3 \%$ of the participants produced "uuh" during hesitation, and the smallest number of participants produced the incoherent sound of "uum" while hesitating. To clarify the numerical description in Table 1 regarding the types of hesitation strategies and application percentage, Figure. 2 is illustrated for a better understanding.

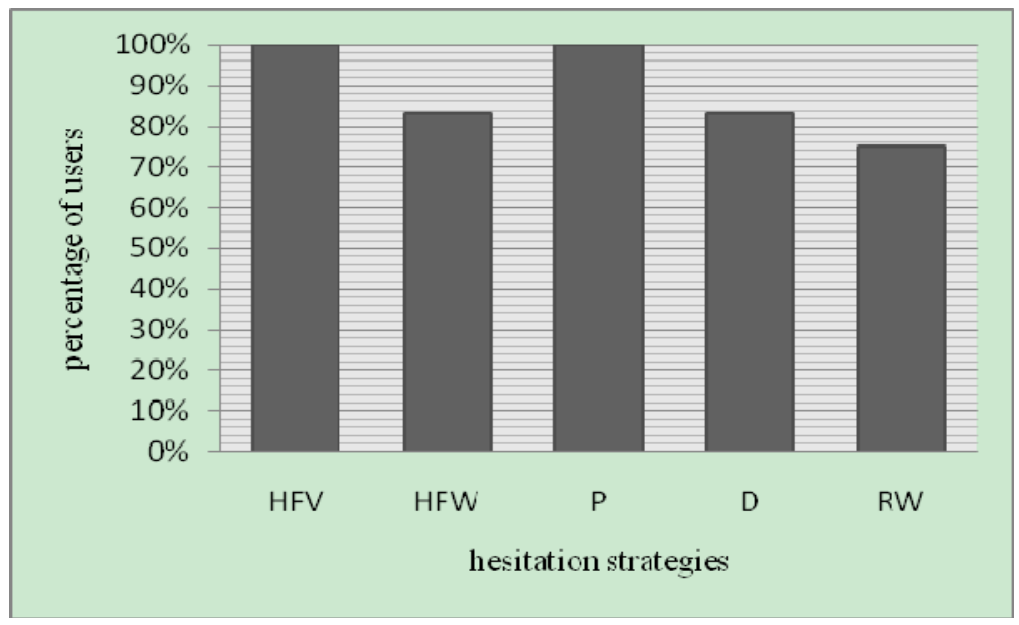

Figure 2. Percentage of using hesitation strategies

For a further detailed analysis, the findings about the percentage of producing "Hesitation Filler as Vocals" are separately illustrated in Figure 3. The identified vocals in the study include "eee", "uuh", "uum", "eem" "mmm" which are individually analyzed by emergence frequencies within the transcriptions. 


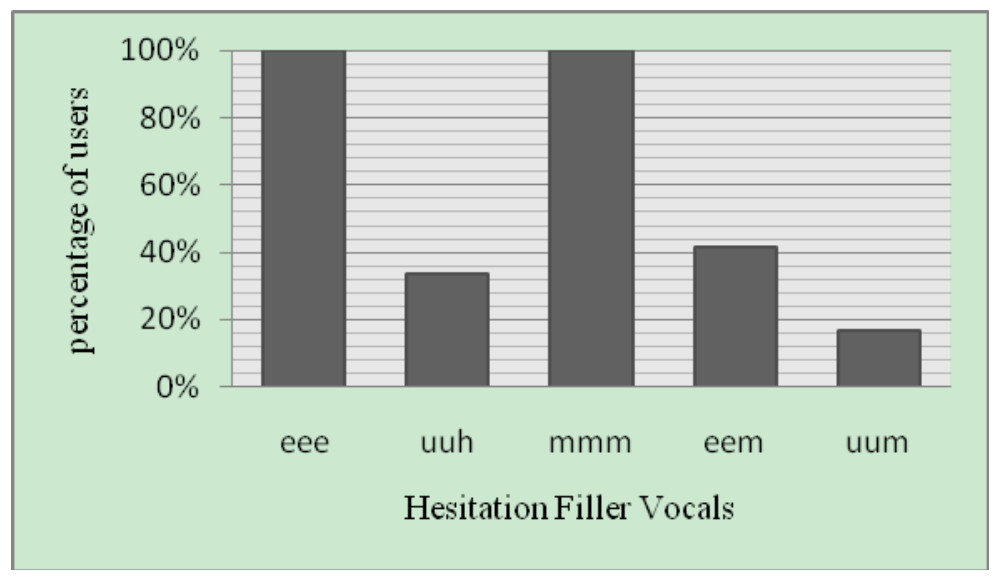

Figure 3. Percentage of producing HFVs

As Figure 3 shows all of the Iranian EFL learners produced "eee" and "mm" during hesitation in L2,but quite a few of them uttered "eem" and "uuh", with the percentage of $34 \%, 42 \%$ respectivelyand only $17 \%$ of the participants produced the incoherent sound of "uum" while thinking about what to say next.

\subsection{Frequency of the Hesitation Discourse Markers}

The total frequency of each hesitation discourse marker is represented in Table 2. The numbers include all of the four contexts of the oral task.

Table 2. Total frequency of hesitation strategies

\begin{tabular}{lllll}
\hline HFV & D & P & RW & H FW \\
\hline 419 & 91 & 65 & 39 & 51 \\
\hline
\end{tabular}

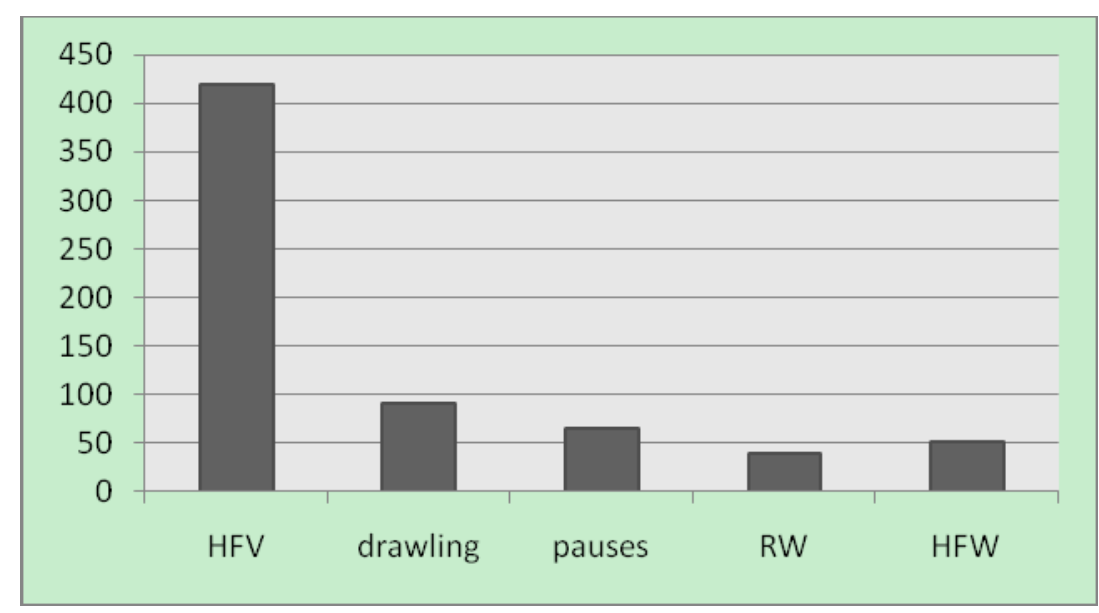

Figure 4. Frequency of hesitation strategies

As it is illustrated in Figure 4, the considerably high frequency of hesitation fillers as vocals has topped all the other types of strategies by the frequency of 419 , which represents the common application of this pragmatic markers among the participants while hesitating. Hesitation filler vocals discovered in the present study include five incoherent sounds as "eee', "uuh", "mmm", "uum", "eem", "mmm", with different frequencies. The second mostly used strategy, although much lower than HFV, but still the second highest, has been identified as drawling with the frequency of 91. It's quite comprehendible from the summary table above that the difference between the frequency of the first and the second highest group is considerable. This explains that producing incoherent vocals likely occurs because of the lack of institutional training to teach the learners how to employ efficient strategies of hesitation. The third most frequent hesitation marker is recorded as pausing with the total 
frequency of 65 which implies that after drawling a word, EFL learners tend to keep silent while thinking what to say next, and in the present study they left the gaps in their speech unfilled for 65 times all through the sessions which again projects the lack of efficient training on L2 communication strategies particularly the hesitation strategies. The next frequent strategy identified belongs to "Hesitation Filler Words" which is always hoped by the instructors to be the main hesitation strategy used by the learners to prove their ability to use language communicatively, but based on the present research it stands before the least frequent hesitation marker with the frequency of 51 which again complies with the claim stated before regarding the lack of effective language training. Finally the least frequent strategy is recorded for repeating words with the frequency of 39. This strategy was employed both on the subject's own word and the researcher's key word which was on the border line of self-clarification and hesitation.

The summary of the findings about the total frequency of these incoherent vocals is included in Table 3 .

Table 3. Hesitation fillers as vocals

\begin{tabular}{ccccc}
\hline eee & uuh & eem & mmm & uum \\
\hline 316 & 45 & 12 & 39 & 7 \\
\hline
\end{tabular}

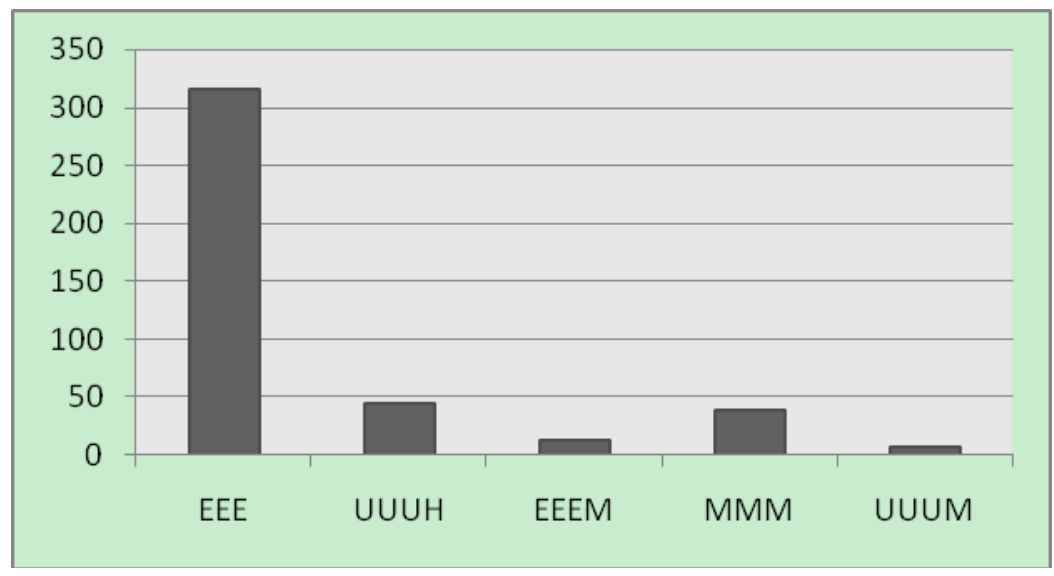

Figure 5. Frequency of HFVs

As Table 3 and Figure 5 represent, the most frequent vocal produced by the participants while hesitating in L2 is the sound "eee" with a considerable frequency of 316. Interestingly, the afore-mentioned vocal is common in the participants' mother tongue too. Then with a sharp decrease, we can notice "uuh" with the frequency of 45 which stands in the second rank among the most frequent vocals produced in this study. The next frequent vocal has been discovered as "mmm" with the frequency of 37, and the last two incoherent sounds produced by the participants indicating hesitation are "eem" and "umm" with the frequency of 12 and 7 respectively.

\section{Conclusion}

The overall aim of this paper was to review the types and frequencies of hesitation strategies used by Iranian EFL learners in oral L2 tests. Based on the findings, it was discovered that the participants of the study were not basically familiar with the application of hesitation strategies in L2 interaction, and all of them produced some incoherent sounds while figuring out what to say next which were mainly adopted from their mother tongue. Moreover, they all kept silent while hesitating which added to their disfluency in L2. It implies that the subjects were not trained efficiently to use the target language communicatively and they were mostly struggling with the linguistic difficulties which are common among EFL learners. The findings also suggested that although not all, but the same number of participants who drawled, tended to use HFWs which comprised $83 \%$ of the total, and finally the least umber of the participants employed the strategy of repeating words. It can be concluded that Iranian EFL learners coming from an expanding circle to the Outer Circle of Malaysia(in this study) struggle with communicative aspect of English which stems from having studied the language institutionally but not pragmatically. Therefore, most of them cannot communicate efficiently and competently with the ESL or native speakers which will all lead to language use frustration. 
Despite the inevitable, constant emergence of filled pauses like uh, um in the spontaneous speech, the findings of the research show that hesitation strategies as a type of communication strategy have been mostly ignored in foreign language teaching of Iran. Perhaps, it is due to the common view of filled pauses as meaningless elements occurring in speech processing difficulties. (Ralph, 2008)

Referring to Bygate (1987) who believes that "EFL teaching is basically struggling with preparing learners to be able to use the language efficiently in a real life condition and employ communication skills in the target language", and the mismatch between what the L2 speakers hold as the linguistic resources and what they actually plan to communicate with the listeners cause some systematic language phenomena rising from communication difficulties or break downs, in which they cannot apply hesitation strategies to avoid sounding disfluent. (Prinyajaran, 2008)

On the other hand, the findings of the study suggested that, the incoherent vocals which were produced quite dramatically in comparison with the other markers represent the lack of communicative strategy training and development of communicative competence in EFL learners.

Finally, the results of the present study contribute to the necessity of instructing English communicatively, and developing communicative competence among EFL learners.

Now, it can be discussed if CSs have such a significant effect on enabling learners to manage communicative language use and overcome their communication problems, why they are not included in language teaching curricula.Following some scholars (Lam \& Wong, 2000; Dornyei, 1995; Lam, 2006; Nakatani, 2005; Brooks, 1992; Willems, 1987) who have been in favor of incorporating CSs in language teaching courses, there have been others (e.g. Bongaerts \& Poulisse, 1989; Paribakht, 1985; Canale \& Swain, 1980) who have opposed the verdict. (Kaivanpanah, Yamouty, \& Karami, 2012: p. 2)

Based on the results of the present study, it can be felt that classroom learners seem to benefit less from their exposure rather than immersion learners. (Freed, Segalowitz, \& Dewey, 2004; Segalowitz \& Freed, 2004), so it can be recommended to value naturalistic input more in teaching curriculum, since it plays a crucial role in the development of hesitation patterns.

Moreover, it can be concluded that the participants of this study found it difficult to recognize the suitable function of different types of hesitation discourse markers which agrees with what Cenoz discuss that inter-language hesitation patterns are different from those used by native speakers (Cenoz, 2000). Also, the results of the study agrees with transferring formal and functional characteristics of native hesitation pattern (as proposed by Schmid and F"agersten (2010) which can be another reason of counting L2 learners as non-native speakers. (Schmid, et al., 2010)

\subsection{Recommendation for Further Research}

Future improvements to this study might develop to other major 'speech error' categories such as false starts and stutters.

Also, the length of producing hesitation fillers is one of the variables which may reveal some significant insights about the relationship of this factor with the reasons and outcomes of it.

Following Bortfeld et al (2001), Merlo \& Mansur (2004) who mentioned the unfamiliarity with the topic to be another effective factor in hesitation, it would be a good idea to develop this study by implementing familiar passages and pictures to make a comparison between the findings of this study which presented unfamiliar passages and pictures to the participants and investigate this claim to discover whether it conforms with their discussion.

Another suggestion for a further research on this study can be testing Oviatt' (1995) idea which believed: "Speakers are more disfluent when they address other humans than machines". In this case one of the sections of the oral test would be providing prompt cards including human issues to one group and machine, or inanimate object issues to another group as the control group and compare the findings.

Moreover, based on the results, it was observed that if the participants of the study were trained for the communication strategies, more specifically here, hesitation strategies, they would have been able to show different oral performance both in quantity and quality of the hesitation strategy application; therefore, in the future researches, a comparison between the speech performance of a trained group and untrained group would reveal interesting findings which contribute to the field of EFL deduction and teaching. In this way, the teach ability of communication strategies will be focused to discover whether training of a specific strategy improves the quantity and quality of learners' strategy application in L2 oral speech. (Yasuo, 2005: p. 3) 


\section{References}

Cenoz, J., \& Jessner, U. (Eds.). (2000). English in Europe, The Acquisition of a Third Language. Clevedon: Multilingual Matters, 271.

Clark,H. H., \& Fox Tree, J. E. (2002). Using uh and um in spontaneous speaking. Cognition, 84, 73-111. http://dx.doi.org/10.1016/S0010-0277(02)00017-3

Corley, M., Stewart, O., \& W. Hesitation. Disfluencies in spontaneous speech: The meaning of um. Department of Philosophy, Psychology, and Language Sciences. University of Edinburgh.

Freed, B. F., Segalowitz, N., \& Dewey, D. P. (2004). Context of learning and second language fluency in French: Comparing a context of learning and second language fluency in French: regular classroom, study abroad, and intensive domestic immersion programs. Studies in Second Language Acquisition, 26, 275-301. Cambridge University Press. http://dx.doi.org/10.1017/S0272263104262064.

Howell, P. (2003). Is a perceptual monitor needed to explain how speech errors are repaired? Proceedings of DiSS'03: Disfluency in Spontaneous Speech Workshop.5-8 September 2003, Göteborg University, Sweden. Robert Eklund (Ed.), Gothenburg Papers in Theoretical Linguistics, 90, 31-34.

Kaivanpanah, Sh., Yamouty, P., \& Karami, H. (2012). Examining the effects of proficiency, gender, and task type on the use of Communication strategies.PortaLinguarum. Enero, 79-93.

Komos, J. (1999). Monitoring and self repairs in L2. Language learning, 49(2), 303-342. http://dx.doi.org/10.1111/0023-8333.00090

Kowal, S., O'Connell, D. C., O'Brien, E. A., \& Bryant, E. T. (1975, December). Temporal Aspects of Reading Aloud and Speaking: Three Experiments. The American Journal of Psychology, 88(4), 549-569. University of Illinois Press. Retrieved from http://www.jstor.org/stable/1421893

Lai, C., Gorman, K., Yuan, J., \& Liberman, M. (2007). Perception of Disfluency: Language Differences and Listener Bias. Department of Linguistics, University of Pennsylvania, Philadelphia, USA.

Menyhárt, K. (2003). Age-dependent types and frequency of disfluencies. Proceedings of DiSS'03: Disfluency in Spontaneous Speech Workshop, 5-8 September 2003, Göteborg University, Sweden. Robert Eklund (Ed.), Gothenburg Papers in Theoretical Linguistics, 90, 45-48.

Nakatani, Y. (2005). The Effects of Awareness-Raising Training on Oral Communication Strategy Use. Modern Language Journal, 89(1), 76-91. Blackwell Publishing. http://dx.doi.org/10.1111/j.0026-7902.2005.00266.x

Nicholson, H., Gurman Bard, E., Lickley, R., Anderson, A. H., Mullin, Jim., Kenicer, D., \& Smallwood, L. (2003). The intentionality of disfluency: Findings from feedback and timing. Proceedings of DiSS'03: Disfluency in Spontaneous Speech Workshop.5-8 September 2003, Göteborg University, Sweden. Robert Eklund (Ed.), Gothenburg Papers in Theoretical Linguistics, 90, 17-20.

Ralph, L. R. (2008). Filled Pauses in Language Teaching: Why and How. In Bulletin of Gunma Prefectural Women's University, 29, 47-64. Northwestern University.

Rieger, C. (2003). Disfluencies and hesitation strategies in oral L2 tests. Proceedings of DiSS'03: Disfluency in Spontaneous Speech Workshop, 5-8 September 2003, Göteborg University, Sweden. Robert Eklund (Ed.), Gothenburg Papers in Theoretical Linguistics, 90, 41-44.

Robert J. Hartsuiker, Corley, M., Lickley, R., \& Russels, M. (2003). Perception of disfluency in people who stutter and people who do not stutter:Results from magnitude estimation. Proceedings of DiSS'03: Disfluency in Spontaneous Speech Workshop. 5-8 September 2003, Göteborg University, Sweden. Robert Eklund (Ed.), Gothenburg Papers in Theoretical Linguistics, 90, 35-37.

Schmid, M. S., Groningen, R., Fa"gersten, K., B., \& H“ogskola, F. S. (2010). Disfluency Markers in L1 Attrition. Language Learning.

Prinyajaran, G., \& Wannaruk, A. (2008). Communication strategies training for science and technology graduate students, School of English, Suranaree University of Technology, Nakhon Ratchasima. Soc, Sci., 2(1), 17-32. Thailand. 


\section{List of Abbreviations}

L1:

The first language, mother tongue

L2:

The second language

ESL:

English as the second language

EFL:

English as a foreign language

EIL:

English as an International Language 